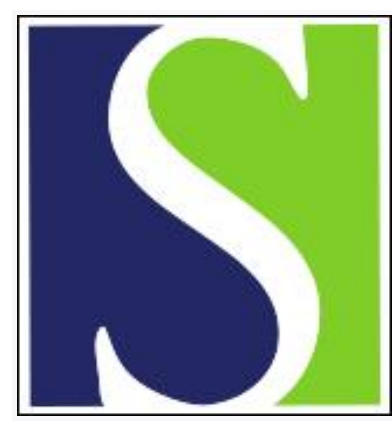

Scand J Work Environ Health 2000;26(5):421-426

https://doi.org/10.5271/sjweh.563

Issue date: Oct 2000

Effects of shift work on 24-hour ambulatory blood pressure and its variability among Japanese workers

by Ohira T, Tanigawa T, Iso H, Odagiri Y, Takamiya T, Shimomitsu T, Hayano J, Shimamoto T

The following article refers to this text: 2011;37(4):263-275

Key terms: anger expression; blood pressure monitoring; circadian rhythm; shift worker; sleep

This article in PubMed: www.ncbi.nlm.nih.gov/pubmed/11103841

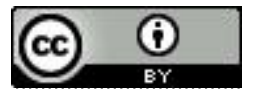




\title{
Effects of shift work on 24-hour ambulatory blood pressure and its variability among Japanese workers
}

\author{
by Tetsuya Ohira, MD, ${ }^{1}$ Takeshi Tanigawa, MD, ${ }^{1}$ Hiroyasu Iso, MD, ${ }^{1}$ Yuko Odagiri, MD, ${ }^{2}$ \\ Tomoko Takamiya, MD, ${ }^{2}$ Teruichi Shimomitsu, MD, ${ }^{2}$ Junichiro Hayano, MD, ${ }^{3}$ Takashi Shimamoto, $M D^{\prime}$
}

\begin{abstract}
Ohira T, Tanigawa T, Iso H, Odagiri Y, Takamiya T, Shimomitsu T, Hayano J, Shimamoto T. Effects of shift work on 24-hour ambulatory blood pressure and its variability among Japanese workers. Scand J Work Environ Health $2000 ; 26(5): 421-426$
\end{abstract}

\begin{abstract}
Objectives This study examined the effects of rotating shift work on blood pressure in a comparison of ambulatory blood pressure and long-term changes in blood pressure between shift and day workers.

Methods Ambulatory blood pressure was measured for 24-hour periods at an interval of 30 minutes for 27 shift workers and 26 day workers when they worked during the day. Blood pressure was compared between these 2 groups of workers for 4 time categories (awake, sleep, nonwork awake, and work periods). Their long-term blood pressures, recorded in annual surveys, were reviewed for long-term changes. These comparisons were adjusted for the effects of body mass index, alcohol intake, anger expression, and physical activity.

Results On the average, sleep time was shorter and the anger-in (ie, anger suppressed) score was higher for the shift workers than for the day workers, but body mass index and alcohol intake did not differ between the 2 groups. Even after adjustment for these co-variables, the mean systolic blood pressure during the 24 -hour, awake, and work periods were higher among the shift workers than among the day workers. The 24-hour standard deviations of the systolic blood pressures were also higher for the shift workers than for the day workers. Among the shift workers, but not among the day workers, a significant long-term increase was observed in systolic blood pressure measured in the annual surveys.
\end{abstract}

Conclusions These results suggest that shift work may increase systolic blood pressure levels among Japanese men.

Key terms anger expression, blood pressure monitoring, circadian rhythm, shift worker, sleep.

Previous prospective cohort studies have shown a higher risk of coronary heart disease among rotating-shift workers than among day workers (1-4) and in part attributed the higher risk to a higher level of serum triglyceride and obesity and to a higher prevalence of smoking. However, the impact of shift work on cardiovascular risk factors, in particular blood pressure levels, has not been well elucidated. A recent prospective study of Japanese men showed that shift workers had a higher risk of developing hypertension than day workers in the age range of $18-29$ years even after adjustment for age, body mass index, alcohol intake, and baseline blood pressure levels (5). The study suggested the adverse effect of shift work on blood pressure, but it evaluated only blood pressure taken under stationary conditions. Given the possible effects of shift work on the circadian rhythm of blood pressure, it is important to observe ambulatory blood pressure to determine the overall effects of shift work.

The aim of the present study was to examine the effects of shift work on ambulatory blood pressure, as well as the long-term effects on changes in blood pressure. Ambulatory blood pressure were recorded every $30 \mathrm{~min}$ utes for 24 hours on a workday. Long-term blood pressure changes were evaluated retrospectively by reviewing blood pressures recorded in annual surveys. Between shift and day workers, we also compared 24-hour blood pressure variability, which is considered to be a useful predictor of target organ damage in hypertension (6). To evaluate the direct effects of shift work on blood pressure, we adjusted the analysis for the effects of factors

1 Institute of Community Medicine, University of Tsukuba, Tsukuba, Japan.

2 Department of Preventive Medicine and Public Health, Tokyo Medical University, Tokyo, Japan.

3 The Third Department of Internal medicine, Nagoya City University Medical School, Nagoya City, Japan.

Reprint requests to: Dr Tetsuya Ohira, Department of Epidemiology and Mass Examination, Osaka Medical Center for Cancer and Cardiovascular Diseases, 1-3-3 Nakamichi, Higashinari-ku, Osaka, 537-8511, Japan. [E-mail: fwge1119@mb.infoweb.ne.jp] 
potentially influencing blood pressure, such as body mass index, alcohol intake, physical activity, and anger expression $(7-10)$.

\section{Subjects and methods}

The survey was conducted in a nuclear power plant (the total number of male workers was 886, including 272 shift workers) in October 1997. In this plant, shift workers were engaged mainly in plant operations. The schedule of the workshifts was as follows: D1-D2-A-N-N-O$\mathrm{O}-\mathrm{O}$ (D1 = day shift 1 , with worktime from 0830 to 1500 ; D2 = day shift 2, with worktime from 0830 to $2100 ; \mathrm{A}=$ afternoon shift, with worktime from 1500 to $2100 ; \mathrm{N}=$ night shift, with worktime from 2100 to 0830 ; $\mathrm{O}=$ day off). Day workers worked mainly in a support or management role and their worktime was from 0830 to 1710 .

\section{Subjects}

The subjects of our study consisted of 27 male shift workers aged 20-45 (mean 31) years and 26 male day workers aged 20-45 (mean 32) years, who were chosen by frequency matching into age groups $(20-29,30-39$, and $40-45$ years). The characteristics of the subjects in both groups are presented in table 1 . The subject distribution for age groups $20-29,30-39$ and $40-45$ years was $56 \%, 22 \%$, and $22 \%$, respectively, for the shift workers and $50 \%, 23 \%$ and $27 \%$, respectively, for the day workers. The 2 groups did not differ in respect to their mean values of age, duration of employment and work under the current work schedules, body mass index, alcohol intake, physical activity, education, or the proportion of smoking. The shift workers had a shorter average sleep time and a higher mean "anger-in" score than the day workers, whereas the mean "anger-out" score did not differ between them. For both groups, the subjects had worked their current schedules for more than 6 months, and none of them had a work absence of longer than 10 days in the 2 months prior to the study. All the subjects had a high school or higher level of education and lived in local communities near the workplace. None of them had a body mass index of $>30 \mathrm{~kg} / \mathrm{m}^{2}$. None had a history of diabetes mellitus, angina pectoris, myocardial infarction, or cerebral infarction or was currently receiving any antihypertensive medication. All the subjects gave their written informed consent to participate in the study.

\section{Data collection}

The subjects received a self-administered questionnaire concerning alcohol intake, smoking habits, physical activity, sleep status, education, and anger expression. They were instructed to report to the health-care office of the plant with the completed questionnaire. The amount of alcohol intake was measured as the corresponding grams of ethanol. Workers smoking $\geq 1$ cigarettes per day were defined as current smokers. To assess physical activity, we used the physical-activity questionnaire developed by Suzuki et al (11). This questionnaire showed adequate levels of validity and test-retest reliability for assessments of daily energy expenditure. Average awake and sleep time was evaluated from a 6-day diary.

To measure anger expression, we used the Japanese version of the selected Anger Expression Scale (12). The Anger Expression Scale, developed by Spielberger et al, is based on the frequency of reactions to anger-provoking situations $(13,14)$. Its frequency was classified as almost never, sometimes, often, or always. The anger expression was subclassified according to the direction of the anger expression: anger expressed behaviorally was regarded as "anger out," anger held in or suppressed was "anger in," and attempts to control anger expression were "anger control". We did not assess anger control in this study, because the Japanese version of the selected Anger Expression Scale did not include the items for anger control and because no relation has been observed between anger control and blood pressure (15). Scores for the items for anger-out and anger-in were summed separately to calculate the respective anger expression scores.

Ambulatory blood pressure was monitored using an automated, portable, noninvasive device (TM2425 or

Table 1. Characteristics (means, standard deviations, or proportions) among rotating-shift and day workers. $(\mathrm{BP}=$ blood pressure)

\begin{tabular}{|c|c|c|c|c|c|c|c|c|c|c|c|c|c|c|}
\hline \multirow[t]{2}{*}{ Group } & \multirow{2}{*}{$\begin{array}{c}\begin{array}{c}\text { Age } \\
\text { (years) }\end{array} \\
\text { Mean SD }\end{array}$} & \multirow{2}{*}{$\begin{array}{c}\text { Employ- } \\
\text { ment } \\
\text { (years) }\end{array}$} & \multicolumn{2}{|c|}{$\begin{array}{c}\text { Present } \\
\text { work } \\
\text { (years) }\end{array}$} & \multirow{2}{*}{$\begin{array}{c}\text { Body } \\
\text { mass } \\
\text { index } \\
\left(\mathrm{kg} / \mathrm{m}^{2}\right)\end{array}$} & \multirow{2}{*}{$\begin{array}{c}\text { Sleep } \\
\text { during } \\
6 \text { days } \\
\text { (hours) } \\
\text { Mean SD }\end{array}$} & \multirow{2}{*}{$\begin{array}{c}\text { Sleep } \\
\text { day } \\
\text { before } \\
\text { BP } \\
\text { monitor- } \\
\text { ing } \\
\begin{array}{l}\text { Mean SD }\end{array}\end{array}$} & \multicolumn{2}{|c|}{$\begin{array}{c}\text { Alcohol } \\
\text { intake } \\
\text { (g/day) }\end{array}$} & \multirow{2}{*}{$\begin{array}{c}\text { Physical } \\
\text { activity } \\
\text { (kcal/ } \\
\text { day) }\end{array}$} & $\begin{array}{c}\text { Anger- } \\
\text { out } \\
\text { (score) }\end{array}$ & \multirow{2}{*}{$\begin{array}{c}\begin{array}{c}\text { Anger- } \\
\text { in } \\
\text { (score })\end{array} \\
\text { Mean SD }\end{array}$} & \multirow{2}{*}{$\begin{array}{c}\begin{array}{c}\text { Edu- } \\
\text { cation } \\
\text { (years) }\end{array} \\
\text { Mean SD }\end{array}$} & $\begin{array}{c}\text { Smokers } \\
(\%)\end{array}$ \\
\hline & & & Mean & $\mathrm{SD}$ & & & & Mean & SD & & Mean SD & & & Mean SD \\
\hline $\begin{array}{l}\text { Shift work- } \\
\text { ers }(N=27)\end{array}$ & 30.58 .5 & $11.4 \quad 8.8$ & 8.2 & 6.8 & $23.1 \quad 2.7$ & $\begin{array}{ll}7.1 & 1.1\end{array}$ & $\begin{array}{ll}7.2 & 1.4\end{array}$ & 19 & 21 & 2088274 & 12.93 .1 & 16.14 .4 & 12.30 .7 & 58 \\
\hline $\begin{array}{l}\text { Day work- } \\
\text { ers }(N=26)\end{array}$ & $31.8 \quad 8.7$ & 12.98 .7 & 7.7 & 8.8 & 23.32 .8 & $\begin{array}{ll}7.6 & 0.7\end{array}$ & $\begin{array}{ll}7.4 & 0.8\end{array}$ & 22 & 18 & 2121339 & $13.1 \quad 3.2$ & 13.23 .4 & $12.4 \quad 1.3$ & 42 \\
\hline
\end{tabular}


TM2421, A \& D Co, Inc, Tokyo, Japan) (16). An appropriately sized cuff was placed on the subject's left arm, and blood pressure was recorded automatically every 30 minutes for 24 hours on 1 of the subject's workdays. For shift workers, ambulatory blood pressure was measured on the D2 shift.

Height in stocking feet and weight in light clothing were measured. The body mass index was calculated as weight $(\mathrm{kg}) /$ height $(\mathrm{m})^{2}$.

In this plant, annual surveys of cardiovascular risk factors had been conducted for more than 25 years. We used the data from these surveys to examine retrospectively the long-term changes in blood pressure and body mass index. We defined the reference blood pressure as that obtained immediately prior to the subjects' beginning their current work schedule. Because 18 out of the 27 shift workers and 10 out of the 26 day workers had been engaged in their current work schedule ever since they joined the company, we used the data obtained from when they first took the survey. The remaining subjects had moved from day work to shift work or vice versa, and for these subjects the data obtained immediately prior to the beginning of the current work schedule were used. The duration of the retrospective observations was 0.5 to 25 (mean 8.5 ) years. The reference systolic and diastolic blood pressures were measured by trained nurses using standard mercury sphygmomanometers on the right arms of seated subjects after they rested for 5 minutes. Data on alcohol intake were not available from the earlier surveys.

\section{Statistics}

The differences in the mean values and proportions between the shift and day workers were evaluated with Student's t-test and the chi-square test, respectively. Ambulatory systolic and diastolic blood pressures were averaged over the 4 time categories of awake, sleep, nonwork awake, and work periods. Blood pressure variability was estimated as the standard deviations of the blood pressures during 24-hour ambulatory monitoring. Differences in the mean systolic and diastolic blood pressures between the shift and day workers were examined with an analysis of covariance adjusting for age (years), body mass index $\left(\mathrm{kg} / \mathrm{m}^{2}\right)$, alcohol intake (never, current $<23$, $23-46,>46$ grams of ethanol per day), blood pressure $(\mathrm{mm} \mathrm{Hg})$ before the current work schedule, tertile of physical activity (1620-1902, 1903-2175, and 2176$2893 \mathrm{kcal} /$ day in total energy expenditure), and tertile of the anger-in score $(8-12,13-16$, and 17-26). Differences in long-term changes in blood pressure were examined using a paired t-test and a repeated-measure analysis of variance (ANOVA) with adjustment for age, body mass index before the current work schedule, and duration of the retrospective observation. The data have been presented as the means and standard deviations, except for the least-square means adjusted for covariates, which have been presented as the least square mean (and the standard error of the mean). All the P-values were tested with the 2-tailed test, and $<0.05$ was the cutoff indicating statistical significance.

\section{Results}

The means of the systolic blood pressures for the 24-hour, awake, and work periods were significantly higher for the shift workers than for the day workers. A similar tendency was observed for the means of the systolic blood pressures for the sleep and nonwork awake periods, but the difference did not reach statistical significance (table 2, see page $424-425$ ). The means of the diastolic blood pressures for the 24-hour, awake, sleep, and work periods did not differ between the shift and day workers. The 24-hour standard deviation of the systolic blood pressure was higher for the shift workers than for the day workers.

Even after adjustment for age, body mass index, daily alcohol intake, physical activity, anger-in score, and blood pressure prior to the beginning of the current work schedule, the group difference in the mean systolic blood pressure remained significant for the awake and work periods (table 3 , see page 424 ).

Table 4 (see page 425) compares the long-term changes in blood pressures and body mass index between the shift and day workers. Increases in the mean values of the body mass index and diastolic blood pressure were similar between the shift and day workers. Systolic blood pressure showed, however, a significant long-term increase for the shift workers but not for the day workers. After adjustment for age, body mass index before the current work schedule, and the duration of the retrograde observation, the shift workers showed a tendency towards a long-term increase in systolic blood pressure [repeated measure ANOVA, $\mathrm{F}(1,48)$ for group $\times$ time interaction effect $=3.37, P=0.07]$.

\section{Discussion}

Our study showed that even when circadian variations in blood pressures were taken into account, shift workers had a higher systolic blood pressure than day workers, particularly during work periods. The 24-hour blood pressure variability was also greater for the shift workers than for the day workers. Furthermore, shift work was associated with a long-term increase in systolic blood pressure in annual surveys. Higher blood pressure and greater blood pressure variability are associated with a higher prevalence of target organ damage and raise the 
Table 2. Ambulatory blood pressure, heart rate, and standard deviation of the 24-hour blood pressure of the rotating-shift and day workers.

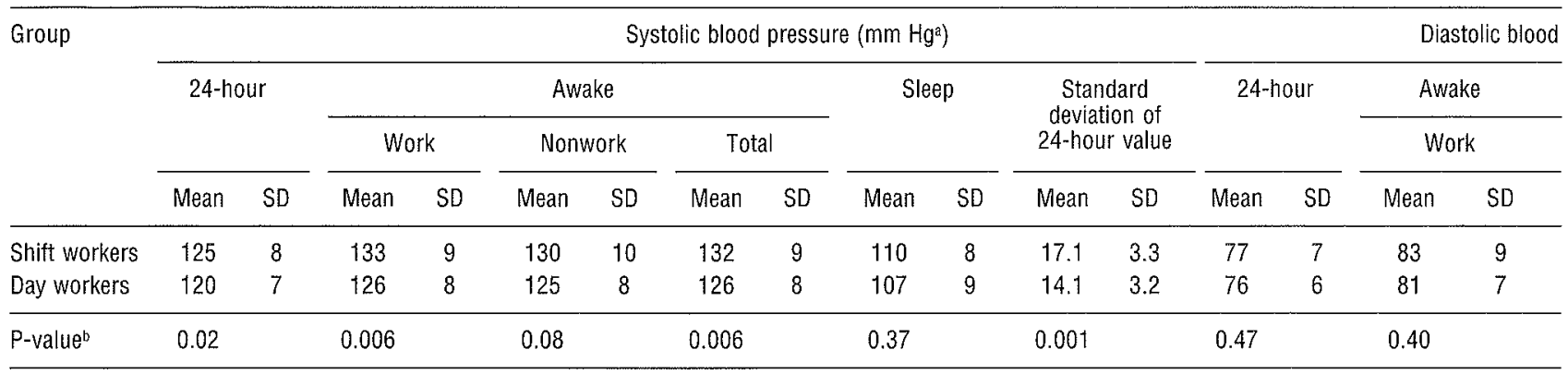

$1 \mathrm{~mm} \mathrm{Hg} \approx 0.133 \mathrm{kPa}$.

b Significance of difference by Student's t-test.

Table 3. Multivariate-adjusted mean systolic blood pressure of the rotating-shift and day workers. (SE = standard error of the mean)

\begin{tabular}{|c|c|c|c|c|c|c|c|c|c|c|c|c|}
\hline \multirow[t]{4}{*}{ Group } & \multicolumn{12}{|c|}{ Systolic blood pressure ( $\mathrm{mm} \mathrm{Hg}$ ) } \\
\hline & \multirow{2}{*}{\multicolumn{2}{|c|}{ 24-hour }} & \multicolumn{6}{|c|}{ Awake } & \multirow{2}{*}{\multicolumn{2}{|c|}{ Sleep }} & \multirow{2}{*}{\multicolumn{2}{|c|}{$\begin{array}{l}\text { Standard deviation } \\
\text { of } 24 \text {-hour value }\end{array}$}} \\
\hline & & & \multicolumn{2}{|c|}{ Work } & \multicolumn{2}{|c|}{ Nonwork } & \multicolumn{2}{|c|}{ Total } & & & & \\
\hline & Mean & SE & Mean & SE & Mean & SE & Mean & SE & Mean & SE & Mean & SE \\
\hline Shift workers & 125 & 1.5 & 132 & 1.6 & 133 & 1.6 & 129 & 1.8 & 109 & 1.6 & 17.5 & 0.6 \\
\hline Day workers & 121 & 1.5 & 126 & 1.6 & 126 & 1.6 & 126 & 1.8 & 108 & 1.6 & 13.7 & 0.7 \\
\hline P-value ${ }^{b}$ & 0.06 & & 0.02 & & 0.01 & & 0.21 & & 0.59 & & 0.0004 & \\
\hline
\end{tabular}

a $1 \mathrm{~mm} \mathrm{Hg} \approx 0.133 \mathrm{kPa}$.

- Significance of difference by analysis of covariance adjusted for age, body mass index, daily alcohol intake, physical activities, anger-in, and systolic blood pressure levels $0.5-25$ years before the present work.

risk of subsequent cardiovascular events $(6,17-20)$. Our results seem to agree with the finding that shift workers have a higher risk of coronary heart disease than day workers $(1-4)$.

The mechanisms for the effects of shift work on blood pressure have not been fully elucidated (5). In our study, the mean sleep time for 6 days was shorter for the shift workers than for the day workers, and this result may explain the higher 24-hour mean systolic blood pressure of the shift workers, although the increase in blood pressure was observed even when analyzed separately for the work and nonwork awake periods. The shorter sleep time among the shift workers, however, may be associated with a higher sympathetic nerve activity. For 18 male workers, Tochikubo et al (16) reported a higher blood pressure and a greater urinary excretion of norepinephrine during the day after 3 to 4 hours of sleep at night than after ordinary amounts of sleep, a finding suggesting that fatigue and mental stress due to insufficient sleep may result in sympathetic activation. Furthermore, we observed greater blood pressure variability among the shift workers than among the day workers. According to Floras et al (21), greater blood pressure variability is a useful index of sympathetic nerve activity, correlating well with the increase in plasma norepinephrine.

We observed a higher "anger-in" score for the shift workers, and this finding may also support the presence of a higher sympathetic nerve activity among shift workers. Esler et al (22) showed that the proportion of men suppressing hostility was $63 \%$ among high-renin hypertensive men, compared with $10 \%$ among normotensive men. These high-renin hypertensives exhibited an increased plasma norepinephrine concentration and showed a reduction to normal blood pressure by pharmacological alpha- and beta-adrenergic blockade. The study suggested that suppressed anger expression may be linked to higher activity of the sympathetic nervous system or the renin-angiotensin system, both of which are major determinants of blood pressure. Earlier cross-sectional studies also showed that suppressed anger or high "anger-in" was positively associated with blood pressure or hypertensive status $(10,23,24)$. Furthermore, a large prospective study indicated that persons with suppressed anger had a higher risk of developing hypertension than persons without suppressed anger (25).

Because job types were different between the shift and day workers, we need to be careful in interpreting the higher blood pressure levels among shift workers at work. The shift workers were engaged mainly in plant operations, while day workers worked mainly in plant support or management. The jobs of the shift workers may have had higher physical job demands than those of day workers. This is an unlikely possibility, however, since the estimated daily energy expenditure did not 


\begin{tabular}{|c|c|c|c|c|c|c|c|c|c|c|c|c|c|c|c|c|c|}
\hline \multicolumn{8}{|c|}{ pressure $\left(\mathrm{mmHg}^{\mathrm{a}}\right)$} & \multicolumn{10}{|c|}{ Heart rate (beats/min) } \\
\hline \multicolumn{4}{|c|}{ Awake (continued) } & \multirow{2}{*}{\multicolumn{2}{|c|}{ Sleep }} & \multirow{2}{*}{\multicolumn{2}{|c|}{$\begin{array}{c}\text { Standard } \\
\text { deviationof } \\
\text { 24-hour value }\end{array}$}} & \multirow{2}{*}{\multicolumn{2}{|c|}{ 24-hour }} & \multicolumn{6}{|c|}{ Awake } & \multirow{2}{*}{\multicolumn{2}{|c|}{ Sleep }} \\
\hline \multicolumn{2}{|c|}{ Nonwork } & \multicolumn{2}{|c|}{ Total } & & & & & & & \multicolumn{2}{|c|}{ Work } & \multicolumn{2}{|c|}{ Nonwork } & \multicolumn{2}{|c|}{ Total } & & \\
\hline Mean & SD & Mean & SD & Mean & SD & Mean & SD & Mean & SD & Mean & SD & Mean & SD & Mean & SD & Mean & SD \\
\hline 81 & 9 & 82 & 8 & 65 & 7 & 12.9 & 2.9 & 69 & 7 & 76 & 10 & 70 & 9 & 74 & 9 & 58 & 6 \\
\hline 79 & 6 & 80 & 6 & 65 & 7 & 11.5 & 2.5 & 66 & 9 & 71 & 9 & 71 & 11 & 71 & 9 & 57 & 9 \\
\hline 0.49 & & 0.30 & & 0.79 & & 0.07 & & 0.18 & & 0.08 & & 0.55 & & 0.26 & & 0.78 & \\
\hline
\end{tabular}

Table 4. Changes in long-term blood pressure and body mass index for the rotating-shift and day workers.

\begin{tabular}{|c|c|c|c|c|c|c|c|c|c|c|c|c|c|c|c|c|c|c|}
\hline \multirow[t]{3}{*}{ Group } & \multicolumn{4}{|c|}{$\begin{array}{c}\text { Age } \\
\text { (years) }\end{array}$} & \multicolumn{4}{|c|}{$\begin{array}{l}\text { Systolic blood pressure } \\
(\mathrm{mm} \mathrm{Hg})^{b}\end{array}$} & \multicolumn{6}{|c|}{$\begin{array}{l}\text { Diastolic blood pressure } \\
\left(\mathrm{mm} \mathrm{Hg}^{b}\right)\end{array}$} & \multicolumn{4}{|c|}{$\begin{array}{l}\text { Body mass index } \\
\qquad\left(\mathrm{kg} / \mathrm{m}^{2}\right)\end{array}$} \\
\hline & \multirow{2}{*}{$\frac{\text { Past }}{\text { Mean SD }}$} & \multirow{2}{*}{$\frac{\text { Present }}{\text { Mean SD }}$} & \multirow{2}{*}{$\begin{array}{l}\text { Change } \\
\text { Mean SL }\end{array}$} & \multirow{2}{*}{ value } & \multirow{2}{*}{$\frac{\text { Past }}{\text { Mean SD }}$} & \multirow{2}{*}{ Present } & \multirow{2}{*}{ Change } & \multirow{2}{*}{ 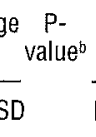 } & \multicolumn{2}{|c|}{ Past } & \multicolumn{2}{|c|}{ Present } & Change & \multirow{2}{*}{${ }^{P-}$} & \multirow{2}{*}{$\frac{\text { Past }}{\text { Mean SD }}$} & \multirow{2}{*}{$\overline{\text { Present }}$} & \multirow{2}{*}{ Change } & \multirow{2}{*}{ value } \\
\hline & & & & & & & & & Mean & SD & Mean & $S D N$ & Mean S & & & & & \\
\hline $\begin{array}{l}\text { Shift } \\
\text { workers } \\
\text { Day }\end{array}$ & 22.17 .4 & 30.58 .5 & $8.4 \quad 6$. & & $121 \quad 12$ & 12810 & 7 & 120.01 & 70 & 11 & 74 & 10 & $4 \quad 1$ & 120.07 & $22.2 \quad 2.4$ & 23.12 .7 & $0.9 \quad 1.9$ & 90.02 \\
\hline workers & 23.35 .7 & 31.88 .7 & 8.68 .4 & . & 12111 & 12310 & 2 & 120.49 & 70 & 8 & 74 & 9 & 41 & 120.07 & 22.22 .8 & 23.32 .8 & 1.12 .4 & $\begin{array}{ll}40.02 \\
\end{array}$ \\
\hline
\end{tabular}

a $1 \mathrm{~mm} \mathrm{Hg} \approx 0.133 \mathrm{kPa}$.

- Significance of difference by paired-sample t-test.

differ between the shift and day workers in our study. Furthermore, the mean heart rate, a useful index of physical activity, did not differ between them.

The workhours on the day of the ambulatory monitoring differed between the shift and day workers (12.5 versus 8.3 hours), and longer workhours among the shift workers might have increased their blood pressure. However, because the total workhours per week ( 42.5 hours) was the same for the shift and day workers, the group difference in blood pressure is unexplained at least as the result of the long-term effects of workhours. Furthermore, the group difference was significant even when we compared the mean blood pressures over an identical work period (0830 - 1710); the mean systolic blood pressure was $133 \mathrm{~mm} \mathrm{Hg}(100 \mathrm{kPa})$ for the shift workers and 127 $\mathrm{mm} \mathrm{Hg}(95.49 \mathrm{kPa})$ for the day workers $(\mathrm{P}=0.015)$. Thus our results may not explain even the short-term effects of longer workhours, at least physically, although we cannot exclude the possible psychological effects of anticipation for longer workhours of the day.

Some previous studies have shown that low socioeconomic status is associated with high blood pressure $(26,27)$. It is plausible that socioeconomic status may confound the relation between shift work and blood pressure. However, in our study, the mean years of education did not differ between the shift and day workers, and these workers lived in the same community. In addition, the mean salary was unlikely to differ between them because the amount of salary is largely decided according to seniority and education.

In conclusion, shift workers have higher levels of systolic blood pressure at work, greater variability in 24hour blood pressure, and a long-term increase in systolic blood pressure levels. These findings suggest that shift work may be linked to an increased risk for cardiovascular diseases.

\section{References}

1. Knutsson A, Akerstedt T, Jonsson BG, Orth-Gomer K. Increased risk of ischaemic heart disease in shift workers. Lancet 1986;2:89-92.

2. Kawachi I, Colditz G, Stampfer M, Willett WC, Manson JE, Speizer FE, et al. Prospective study of shift work and risk of coronary heart disease in women. Circulation 1995;92:317882.

3. Tenkanen L, Sjöblom T, Kalimo R, Alikoski T, Härmä M. Shift work, occupation and coronary heart disease over 6 years of follow-up in the Helsinki Heart Study. Scand J Work Environ Health 1997;23:257-65.

4. Tenkanen L, Sjöblom T, Härmä M. Joint effect of shift work and adverse life-style factors on the risk of coronary heart disease. Scand J Work Environ Health 1998;24(5):351-7.

5. Morikawa Y, Nakagawa H, Miura K, Ishizaki M, Tabata M, 
Nishijo M, et al. Relationship between shift work and onset of hypertension in a cohort of manual workers. Scand J Work Environ Health 1999;25(2): $100-4$.

6. Frattola A, Parati G, Cuspidi C, Albini F, Mancia G. Prognostic value of 24-hour blood pressure variability. J Hypertens 1993;11:1133-7.

7. Klatsky AL, Freidman GD, Siegelaub AB, Gerard MJ. Alcohol consumption and blood pressure. $N$ Engl J Med 1977;296:1194-200.

8. Iso H, Kitamura A, Shimamoto T, Sankai T, Naito Y, Sato S, et al. Alcohol intake and the risk of cardiovascular disease in middle-aged Japanese men. Stroke 1995;26:767_-73.

9. Naito Y. Relationship between physical activity and health examination variables in male workers-new methods to assess physical activity and their applications to epidemiologic research [in Japanese]. Jpn J Public Health 1994;41:706-19

10. Harburg E, Erfurt JC, Hauenstein LS, Chape C, Schull WJ, Schork MA. Socio-ecological stress, suppressed hostility, skin color, and black-white male blood pressure: Detroit. Psychosom Med 1973;35:276-96.

11. Suzuki I, Kawakami N, Shimizu H. Reliability and validity of a questionnaire for assessment of energy expenditure and physical activity in epidemiological studies. J Epidemiol 1998;8:152-9.

12. Ohira $\mathrm{T}$, Iso $\mathrm{H}$, Tanigawa $\mathrm{T}$, Sankai $\mathrm{T}$, Imano $H$, Okamura $\mathrm{T}$, et al. Validity and reliability of the Japanese version of the selected Anger Expression Scale and age, sex, occupation and regional differences in anger expression among Japanese. J Epidemiol 2000;10:118-23.

13. Spielberger CD, Johnson EH, Russell SF, Crane RH, Worden TJ. The experience and expression of anger: construction and validation of an anger expression scale. In: Chesney MA, Rosenman RH, editors. Anger and hostility in cardiovascular and behavioral disorders. New York (NY): Hemisphere/McGraw Hill, 1985: 5-30.

14. Spielberger CD. Manual for the State-Trait Anger Expression Scale (STAX). Odessa (FL): Psychological Assessment Resources Inc, 1988.

15. Ohira T, Tanigawa $\mathrm{T}$, Iso H, Sankai T, Imano H, Shimamoto $\mathrm{T}$. Impact of anger expression on blood pressure levels in white-color workers with low-coping behavior. Environ Health Prev Med 2000;5:37-42.

16. Tochikubo O, Ikeda A, Miyajima E, Ishii M. Effects of insuf- ficient sleep on blood pressure monitored by a new multibiomedical recorder. Hypertension 1996;27:1318-24.

17. Perloff D, Sokolow M, Cowan R. The prognostic value of ambulatory blood pressure. JAMA 1983;249:2792—8

18. Perloff D, Sokolow M, Cowan RM, Juster RP. Prognostic value of ambulatory blood pressure measurements: further analyses. J Hypertens 1989;7 suppl 3:s3-s10.

19. Parati G, Pomidossi G, Albini F, Malaspina D, Mancia G Relationship of 24-hour blood pressure mean and variability to severity of target-organ damage in hypertension. J Hypertens 1987;5:93-8.

20. Palatini P, Penzo M, Racioppa A, Zugno E, Guzzardi G, Anaclerio $\mathrm{M}$, et al. Clinical relevance of nightime blood pressure and of daytime blood pressure variability. Arch Intern Med 1992;152:1855-60.

21. Floras JS, Hassan MO, Jones JV, Osikowska BA, Sever PS Sleight $\mathrm{P}$. Factors influencing blood pressure and heart rate variability in hypertensive humans. Hypertension 1988;11:273-81.

22. Esler M, Julius S, Zweifler A, Randall O, Harburg E, Gardiner $\mathrm{H}$, et al. Mild high-renin essential hypertension: neurogenic human hypertension? N Engl J Med 1977;296:405-11.

23. Johnson EH, Spielberger CD, Worden TJ, Jacobs GA. Emotional and familial determinants of elevated blood pressure in black and white adolescent males. J Psychosom Res 1987;31:287-300

24. Cottington EM, Matthews KA, Talbott E, Kuller LH. Occupational stress, suppressed anger, and hypertension. Psychosom Med 1986;48:249—60.

25. Julius M, Harburg E, Cottington EM, Johnson EH. Angercoping types, blood pressure, and all-cause mortality: a follow-up in Tecumseh, Michigan (1971-1983). Am J Epidemiol 1986; $124: 220-33$.

26. Dyer AR, Stamler J, Shekelle RB, Schoenberger J. The relationship of education to blood pressure: findings on 40,000 employed Chicagoans. Circulation 1976;54:987-92.

27. Keil JE, Tyroler HA, Sandifer SH, Boyle E Jr. Hypertension effects of social class and racial admixture: the results of a cohort study in the black population of Charleston, South Carolina. Am J Public Health 1977;67:634-9.

Received for publication: 28 December 1999 